\title{
PELATIHAN KEWIRAUSAHAAN \\ "PEMBERDAYAAN PKK BIBIS LUHUR RW 22 SEBAGAI PKK YANG SIAP BERBISNIS"
}

\author{
Dian Indriana Hapsari, Sugiarti, Sugiyarmasto, Yustinus Joko D.N, Endang Widyastuti \\ Universitas Setia Budi Surakarta
}

\begin{abstract}
Entrepreneurship has a lot of sense, according to Thomas W. Zimmerer, entrepreneurship is the application of new innovation and creativity for solving problems and take advantage of the opportunities that a person faces every day.

The purpose of this "Pengabdian Masyarakat" is to provide training and knowledge of entrepreneurship to the PKK in RW 22 Nusukan to be able to independently and develop the region as a center of RW 22 Nusukan home industry pastries in Surakarta.

The conclusion of the implementation activities of the Entrepreneurship Training "Empowerment PKK RW 22 Nusukan As the PKK is ready to Business" carried out smoothly. In addition, participants are also expected to understand the importance of entrepreneurship to improve the economy in an increasingly difficult economic.
\end{abstract}

Keywords : Entrepreneur, motivation

\section{PENDAHULUAN}

Banyak sekali orang yang ingin berwirausaha sendiri daripada harus kerja di perusahaan sebagai karyawan. Banyak orang yang memiliki persepsi bahwa meskipun usahanya kecil tetapi ia menjadi Bos, beda hal nya dengan kerja di perusahaan orang lain, setinggi-tingginya jabatan di kantornya ia tetap menjadi karyawan. Karyawan tentu saja lebih sering dapat perintah daripada memerintah, dan sangat terikat waktu kerja. Oleh karena itulah orang-orang lebih memilih berwirausaha. Tetapi menjadi seorang wirausahawan itu tidaklah mudah, kita harus memiliki jiwa kreatif dan inovatif. Sebelum mempelajari seluk beluk tentang kewirausahaan, terlebih dahulu anda harus mengetahui dan memahami pengertian dari kewirausahaan.

Kewirausahaan memiliki banyak pengertian, secara etimologi, kewirausahaan berasal dari kata (ke- : yang memiliki ciri), (wira : berani) dan (usaha : pekerjaan, daya upaya, perbuatan), atau dalam bahasa Inggrisnya adalah enterpreunership. Kata entrepreneur sendiri berasal dari bahasa Perancis yaitu entreprende yang berarti petualang, pengambil risiko, kontraktor, pengusaha (orang yang mengusahakan suatu pekerjaan tertentu), dan pencipta yang menjual hasil ciptaannya. Dalam $\mathrm{KBBI}$ wirausaha sama dengan wiraswasta yaitu orang yg pandai atau berbakat mengenali produk baru, menentukan cara produksi baru, menyusun operasi untuk pengadaan produk baru, memasarkannya, serta mengatur permodalan operasinya.

Nusukan merupakan salah satu kecamatan yang ada di Surakarta yang terdiri dari beberapa kelurahan, salah satunya RW 22 Nusukan. RW ini merupakan RW yang penduduknya cukup padat dan bermata pencaharian bermacam-macam, akan tetapi masih banyak warga RW 22 terutama ibu-ibu baik yang tua maupun yang masih muda yang tidak bekerja, ibu-ibu ini tergabung dalam program PKK yang aktif diselenggarakan tanggal 15 setiap bulan. Berdasarkan analisa situasi di RW 22 
inilah tim program pengabdian masyarakat Universitas Setia Budi memiliki inisiatif untuk memberikan pelatihan pembuatan kue kering agar tercipta wirausaha baru di RW 22 agar ibu-ibu di RW ini memiliki kesibukan dan mampu membantu perekonomian keluarga. Berdasarkan analisis situasi diatas, didapatkan rumusan masalah sebagai berikut: Bagaimana membuat ibu-ibu PKK di RW 22 Nusukan menjadi produktif dan mampu berbisnis untuk menignkatkan kesejahteraan ekonomi keluarga?

\section{METODE}

Kegiatan pengabdian kepada masyarakat ini dilaksanakan melalui metode penyuluhan dan pelatihan. Pentingnya pelatihan kewirausahaan di RW 22 Nusukan ini tidak lain adalah agar tercipta wirausaha baru ditengah sulitnya perekonomian di Indonesia. Wirausaha merupakan salah satu langkah yang harus ditempuh ketika kita dihadapkan pada kebutuhan ekonomi yang semakin sulit Untuk memecahkan permasalahan tersebut digunakan beberapa metode yaitu pelatihan kewirausahaan pembuatan kue kering dengan tujuan agar dapat membuka peluang kerja baru dan RW 22 menjadi pusat home industry kue kering. Metode tersebut dapat dilihat dalam tabel berikut:

Tabel 1. Metode Penyuluhan dan Pelatihan

\begin{tabular}{|l|l|l|}
\hline \multicolumn{1}{|c|}{ Awal } & \multicolumn{1}{|c|}{ Pelatihan } & \multicolumn{1}{c|}{ Outcome } \\
\hline Kegiatan ibu-ibu PKK & Pelatihan kewirausahaan & Diharapkan ibu-ibu PKK yang \\
yang tidak bekerja hanya & pembuatan kue kering & tidak bekerja ini mampu \\
berdiam diri dirumah & & berbisnis kue kering dirumah \\
dengan kesibukan & & masing-masing sambil \\
mengurus anak saja & & mengurus anak dan RW 22 \\
& & $\begin{array}{l}\text { Nusukan bisa dijadikan pusat } \\
\text { home industry kue kering di }\end{array}$ \\
& & kota Surakarta \\
\hline
\end{tabular}

\section{HASIL DAN PEMBAHASAN}

Program penerapan pengabdian masyarakat ini dihadiri oleh 47 peserta dari 60 undangan yang disebar. Program pelatihan menggunakan media penyuluhan dan pelatihan langsung oleh 5 orang dosen dengan kompetensi Manajemen, Akuntansi, dan Psikologi yang dibantu oleh dua orang pelatih yang memang ahli dalam proses pembuatan kue kering serta 10 orang mahasiswa. Materi penyuluhan dan pelatihan langsung dibagikan kepada peserta. Berikut tabel ketercapaian penyuluhan dan pelatihan serta gambar proses pelaksanaan yang telah dilaksanakan:

Tabel 2. Ketercapaian Kegiatan

\begin{tabular}{|l|l|l|}
\hline No. & \multicolumn{1}{|c|}{ Uraian } & \multicolumn{1}{|c|}{ Ketercapaian Target Luaran } \\
\hline 1. & $\begin{array}{l}\text { Koordinator pelaksanaan kegiatan } \\
\text { dan presentasi materi pelatihan } \\
\text { pengantar kewirausaan }\end{array}$ & $\begin{array}{l}\text { Peserta memperhatikan dan berperan aktif } \\
\text { dalam kegiatan diskusi }\end{array}$ \\
\hline 2. & Strategi Pemasaran & $\begin{array}{l}\text { Peserta memperhatikan dan berperan aktif } \\
\text { dalam kegiatan dalam kegiatan diskusi dan } \\
\text { mampu memahami cara-cara pemasaran } \\
\text { produk kue kering }\end{array}$ \\
\hline 3. & Perhitungan Biaya & $\begin{array}{l}\text { Peserta memperhatikan dan menyimak } \\
\text { penjelasan serta mampu membuat analisa } \\
\text { kebutuhan }\end{array}$ \\
\hline
\end{tabular}




\begin{tabular}{|l|l|l|}
\hline No. & \multicolumn{1}{|c|}{ Uraian } & \multicolumn{2}{|c|}{ Ketercapaian Target Luaran } \\
\hline 4. & Motivasi berwirausaha & $\begin{array}{l}\text { Peserta memperhatikan dan menyimak } \\
\text { penjelasan }\end{array}$ \\
\hline 5. & Strategi Manajemen & $\begin{array}{l}\text { Peserta memperhatikan dan menyimak } \\
\text { penjelasan dan mampu mengelola tim }\end{array}$ \\
\hline 6. & Pelatihan Pembuatan Kue Kering & $\begin{array}{l}\text { Peserta memperhatikan, menyimak, dan } \\
\text { mempraktekkan cara membuat kue kering }\end{array}$ \\
\hline
\end{tabular}

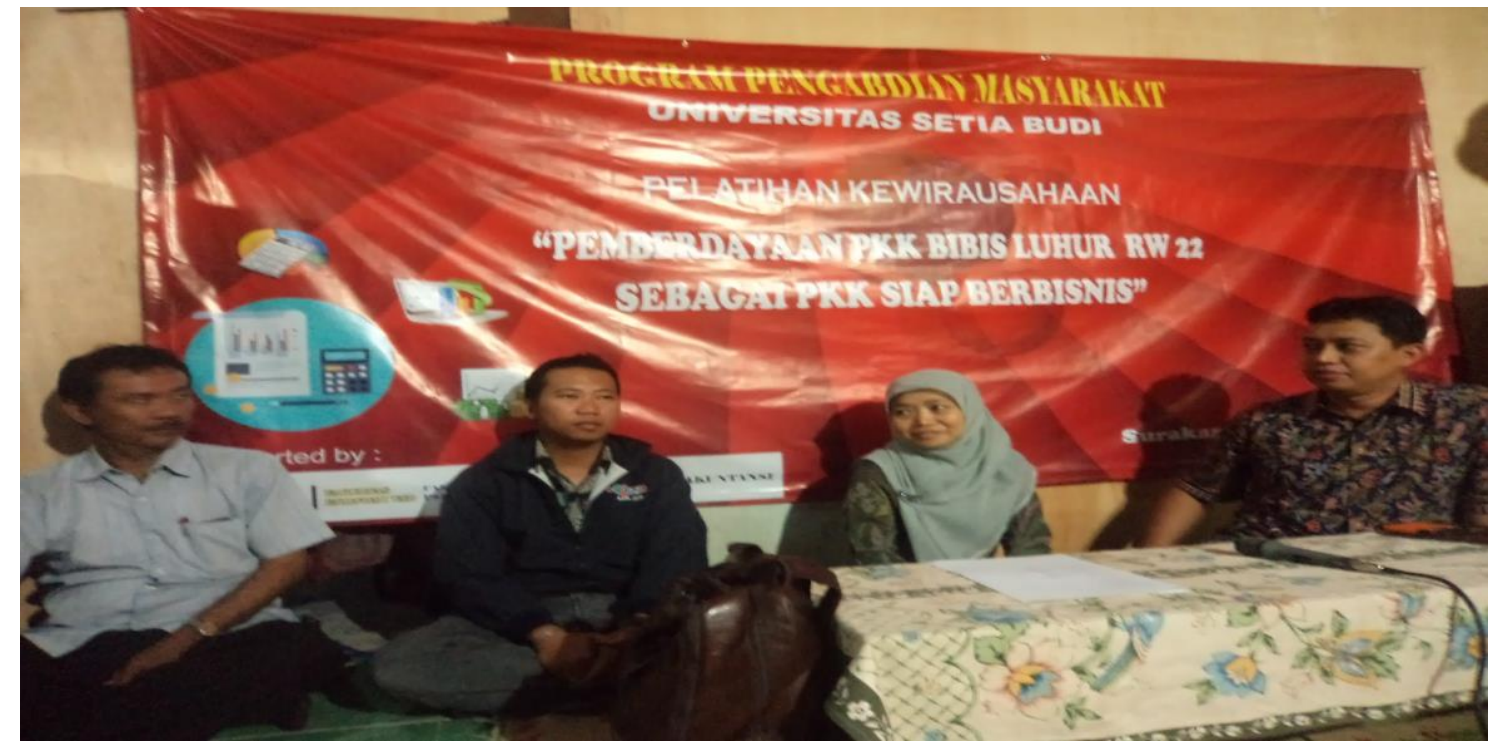

Gambar 1. Penyampaian Materi

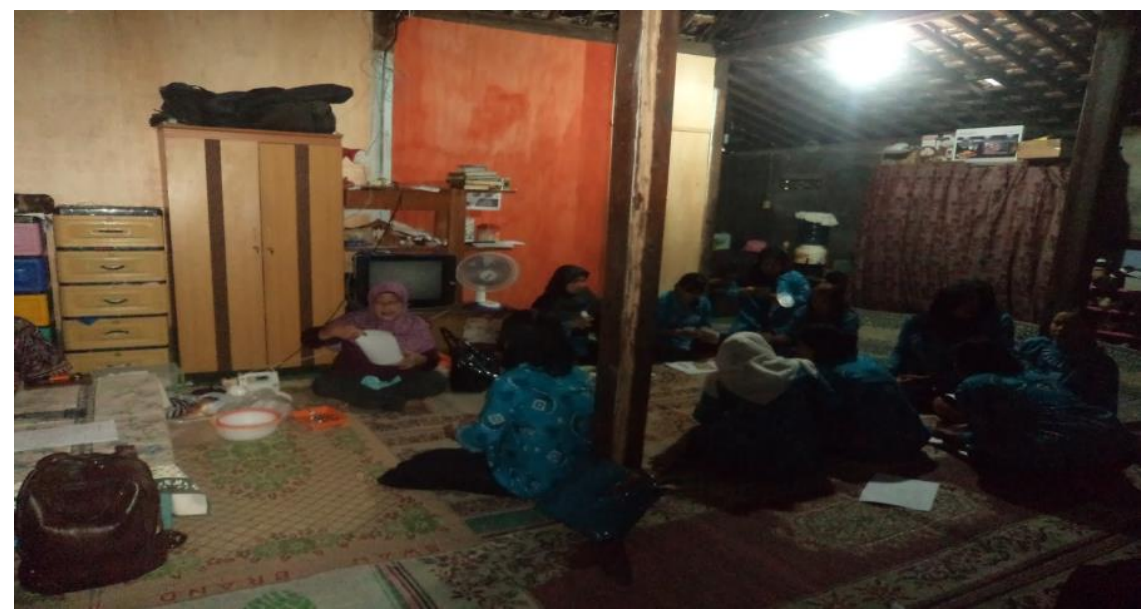

Gambar 2. Penjelasan Pembuatan Kue Kering 


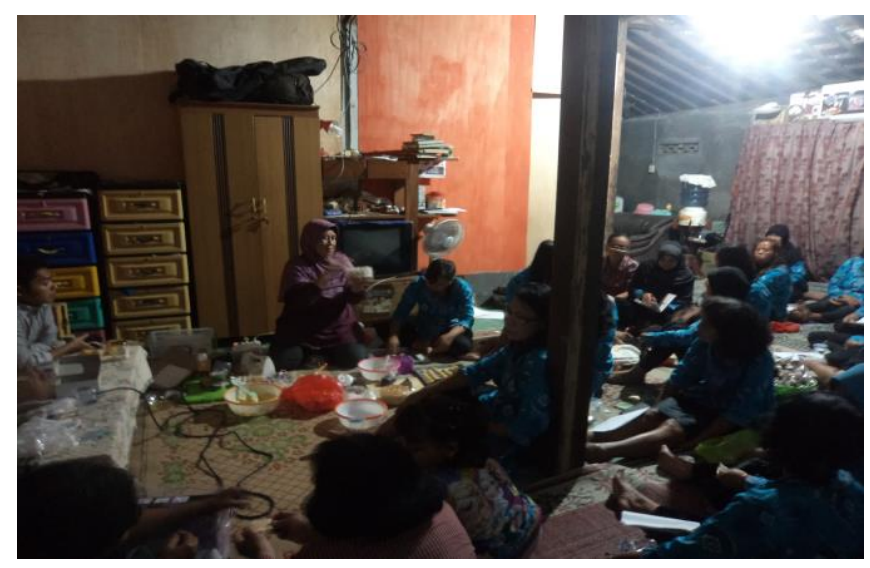

Gambar 3. Pelatihan Pembuatan Kue Kering

\section{KESIMPULAN}

Melalui program pengabdian masyarakat yang telah dilaksanakan, dapat ditarik kesimpulan bahwa:

a. Kegiatan pelaksanaan Pelatihan Kewirausahaan "Pemberdayaan ibu-ibu PKK RW 22 Nusukan Sebagai PKK siap Berbisnis" terlaksana dengan lancar.

b. Peserta dapat memahami pentingnya berwirausaha untuk memperbaiki ekonomi di masa ekonomi yang semakin sulit.

c. Peserta memiliki ketrampilan membuat kue kering dan siap berbisnis.

\section{UCAPAN TERIMA KASIH}

Puji syukur penulis panjatkan kehadirat Allah Tuhan Yang Maha Esa atas rahmat dan hidayahnya rencana kegiatan pengabdian masyarakat dapat terselenggara dengan baik dan lancar. Penulis menyadari bahwa banyak pihak yang telah membantu selama kegiatan. Pada kesempatan ini, penulis mengucapkan terima kasih kepada Yayasan Pendidikan Setia Budi yang telah mendanai kegiatan pengabdian kepada masyarakat ini dan warga RW 22 Nusukan Surakarta yang telah berpartisipasi aktif pada kegiatan ini

\section{DAFTAR PUSTAKA}

Kotler, Philip. 2001. Manajemen Pemasaran di Indonesia : Analisis, Perencanaan, Implementasi dan Pengendalian. Salemba Empat. Jakarta.

Stanton, William J. 2001. Prinsip Pemasaran. Erlangga. Jakarta.

Swastha, Basu dan Irawan. 2005, Manajemen Pemasaran Modern, Liberty, Yogyakarta.

http://repository.library.uksw.edu/bitstream /handle/123456789/1281/

http://ediharukaze.blogspot.co.id/2013/04/ pengertian-kewirausahaandan.html

http://www.iskandarst.com/motivasi-untukberwirausaha/

http://ekonomiplanner.blogspot.co.id/2014/ 06/pengertian-teori-manajemenstrategi.html 